\title{
Pengaruh Kekasaran Permukaan terhadap Performa Slider Bearing Bertekstur dengan Menggunakan Pendekatan CFD
}

\author{
Mohammad Tauviqirrahman*, Mufti M. Suryaman, Muchammad \\ Laboratorium Perancangan Teknik dan Tribologi, Departemen Teknik Mesin, Fakultas Teknik, Universitas Diponegoro \\ Jl. Prof. Sudharto, SH., Tembalang-Semarang 50275, Telp. +62247460059 \\ *E-mail: mtauviq99@yahoo.com
}

\begin{abstract}
In the traditional hydrodynamic lubrication theory, the assumption of perfectly smooth bearing surfaces is often adopted. However, it has been examined that such assumption is unrealistic because in general no surfaces are smooth. The present paper investigates the effect of surface roughness on the performance of textured slider bearing using CFD (computational fluid dynamic) approach. The multi-phase cavitation model is used to model cavitation phenomena in more real way. The performance of rough slider bearing is compared with a corresponding smooth slider bearing varying the inertia conditions. Based on the simulation results, it is found that hydrodynamic pressure and load support decrease with surface roughness. It is also highlighted that if the bearing is designed to have low inertia, the load support will become larger.
\end{abstract}

Keywords: CFD (Computational fluid dynamic), inertia, cavitation, surface roughness, lubrication

\begin{abstract}
Abstrak
Dalam teori pelumasan klasik hidrodinamika, asumsi permukaan kontak bearing yang benar-benar halus sering kali digunakan. Meskipun demikian, telah dibuktikan bahwa asumsi tersebut tidak realistis dikarenakan pada umumnya, tidak ada permukaan bearing yang benar-benar halus. Tulisan ini membahas pengaruh kekasaran permukaan terhadap performa slider bearing bertektur dengan menggunakan pendekatan CFD (computational fluid dynamic). Model kavitasi multi-phase digunakan untuk memodelkan fenomena kavitasi yang lebih riil. Performa slider bearing dengan tingkat kekasaran permukaan tertentu dibandingkan dengan slider bearing halus dengan menvariasikan kondisi inersia. Berdasarkan hasil simulasi, ditemukan bahwa tekanan hidrodinamik dan daya dukung beban berkurang dengan bertambahnya kekasaran permukaan. Selain itu, jika bearing dirancang agar memiliki kondisi inersia yang rendah, daya dukung beban akan menjadi lebih besar.
\end{abstract}

Kata kunci: CFD (Computational fluid dynamic), inersia, kavitasi, kekasaran permukaan, pelumasan

\section{Pendahuluan}

Salah satu komponen penting yang terdapat pada mesin yang berfungsi untuk menahan elemen mesin yang berputar adalah bearing. Bearing digunakan sebagai pemisah sebuah sumbu poros pada mesin agar tidak terjadi kontak antara poros dan penumpunya. Pelumas pada bearing ada berbagai jenis, salah satunya dengan menggunakan fluida.

Berdasarkan hasil penelitian yang ada, performa slider bearing berupa daya dukung beban dapat ditingkatkan dengan menambahkan tekstur pada permukaan bearing [1-4]. Meskipun demikian, pemberian tekstur ini ternyata juga memiliki efek lain pada pelumas yaitu memunculkan terjadinya fenomena kavitasi [5]. Kavitasi ini muncul karena adanya penurunan tekanan pada perubahan luas permukaan secara tiba-tiba pada bearing. Akibat dari kavitasi pada sebuah komponen adalah munculnya gelembung-gelembung udara yang sangat kecil dan menabrak permukaan yang bisa menyebabkan kerusakan komponen [1]. Dari penelusuran pustaka terkait dengan analisis pelumasan dalam bearing, asumsi permukaan bearing yang benar-benar halus masih sering digunakan. Padahal, berdasarkan teknologi pengukuran terbaru, terutama pada skala mikro, tidak ada satupun permukaan yang benar-benar halus bahkan ketika permukaan bearing tersebut sudah mengalami pemolesan (polishing) [6-8].

Atas dasar main-frame inilah dalam penelitian ini, pengaruh kekasaran permukaan terhadap performa pelumasan slider bearing bertekstur akan diteliti lebih lanjut terkait dengan pengaruh adanya kavitasi. Dalam penelitian ini, model kavitasi multi-phase digunakan. Model ini memungkinkan perubahan fasa pelumas dapat dihitung sehingga kondisi riil operasi bearing menjadi lebih representatif dibanding menggunakan model yang lain. Selain itu, pola geometri tekstur pada bearing juga divariasikan untuk menciptakan efek inersia.

\section{Material dan metode penelitian}

\subsection{Persamaan umum}

Persamaan yang digunakan adalah persamaan Navier-Stokes dan kontinuitas yang dipecahkan dengan menggunakan metode volume hingga. Persamaan tersebut mengasumsikan densitas dan viskositas konstan, tanpa 
melibatkan gaya bodi. Kondisi steady dan pemecahan dalam arah dua dimensi (x dan z) juga digunakan. Persamaan Navier-Stokes dan kontinuitas diekspresikan sebagai berikut:

$$
\begin{gathered}
\rho(\mathbf{u} \square \nabla) \mathbf{u}=-\nabla p+\eta \nabla^{2} \mathbf{u} \\
\nabla \square \mathbf{u}=0
\end{gathered}
$$

\subsection{Pemodelan kekasaran permukaan}

Dalam penelitian kali ini, kekasaran permukaan dimodelkan sebagai uniform sand-grain yang dinotasikan dengan parameter ketinggian kekasaran $K_{s}$. Menurut Adams dkk. [9], hubungan antara $K_{s}$ and $R_{a}$ (kekasaran rata-rata aritmatik) dapat ditulis sebagai berikut:

$$
K_{s}=5.863 R_{a}
$$

\subsection{Pemodelan kavitasi}

Untuk mencapai hasil yang lebih akurat, model kavitasi multi-phase digunakan. Dalam model ini, perubahan fasa dari liquid ke uap air dimungkinkan. Transfer massa liquid-uap air (evaporasi dan kondensasi) dimodelkan dengan menggunakan persamaan transport uap air [10]:

$$
\frac{\partial}{\partial t}\left(\alpha_{v} \rho_{v}\right)+\nabla \cdot\left(\alpha_{v} \rho_{v} \mathrm{v}\right)=R_{g}-R_{c}
$$

dimana $\alpha_{v}$ adalah fraksi volume vapour dan $\rho_{v}$ adalah densitas vapor. $R_{g}$ dan $R_{c}$ merujuk kepada transfer massa antara fasa liquid dan fasa vapour dalam kavitasi. Untuk model Zwart-Gelber-Belamri, bentuk akhir persamaan kavitasi adalah sebagai berikut [10]:

Jika $p \leq p_{v}$,

$$
\text { maka } R_{g}=F_{\text {evap }} \frac{3 \alpha_{\text {nuc }}\left(1-\alpha_{v}\right) \rho_{v}}{R_{\mathrm{B}}} \sqrt{\frac{2}{3} \frac{\mathrm{P}_{v}-\mathrm{P}}{\rho_{\ell}}}
$$

Jika $p \geq p_{v}$,

$$
\text { maka } R_{c}=F_{\text {cond }} \frac{3 \alpha_{v} \rho_{v}}{R_{\mathrm{B}}} \sqrt{\frac{2}{3} \frac{\mathrm{P}-\mathrm{P}_{v}}{\rho_{\ell}}}
$$

dimana $F_{\text {evap }}=$ koefisien evaporasi $=50, F_{\text {cond }}=$ koefisien kondensasi $=0.01, R_{B}=$ radius gelembung-gelembung udara $=10^{-6} \mathrm{~m}, \alpha_{\text {nuc }}=$ fraksi volume situs nukleasi $=5 \times 10^{-4}, \rho_{l}=$ densitas liquid dan $p_{v}=$ tekanan uap air.

\subsection{CFD model}

Gambar 1 menunjukkan skema slider bearing bertekstur dengan satu sel tekstur yang diadopsi dari hasil penelitian Dobrica dan Filllon [11]. Dalam simulasi kali ini, untuk menvariasikan pengaruh kondisi inersia, ada dua pola slider bearing bertekstur yang digunakan, yaitu pola dengan pengaruh inersia tinggi $(\lambda=2, \operatorname{Re}=57.3)$, dan pola dengan pengaruh inersia rendah $(\lambda=20, \operatorname{Re}=5.73)$. Re adalah bilangan Reynolds dan $\lambda$ adalah aspek rasio tekstur $(\lambda=1 \mathrm{D} / \mathrm{hd})$. Untuk kedua pola, diasumsikan bahwa texture density (ld/lc) adalah konstan sebesar 0.5 , dan relative dimple depth (ld/hd) adalah sebesar 1.0. Dengan asumsi tersebut, lc dan ld pada kedua pola dibuat konstan, yakni lc $=0.8 \mathrm{~mm}$ serta ld $=0.4 \mathrm{~mm}$. Untuk simulasi bearing ini, kondisi batas periodik digunakan pada sisi inlet dan outlet seperti ditunjukkan dalam Gambar 1. Sedangkan perbandingan dua pola bearing yang berbeda keadaan inersia ini disajikan dalam Gambar 2. Adapun pendefinisian fasa secara detil disajikan dalam Tabel 1.

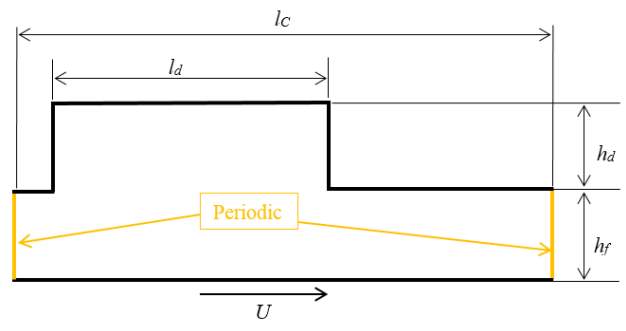

Gambar 1. Skema slider bearing bertekstur (Catatan: $h_{d}=$ ketebalan tekstur, $h_{f}=$ ketebalan film pelumas, $l_{\mathrm{d}}=$ panjang tekstur, $l_{c}=$ panjang zona bertekstur, $U=$ kecepatan sliding) 


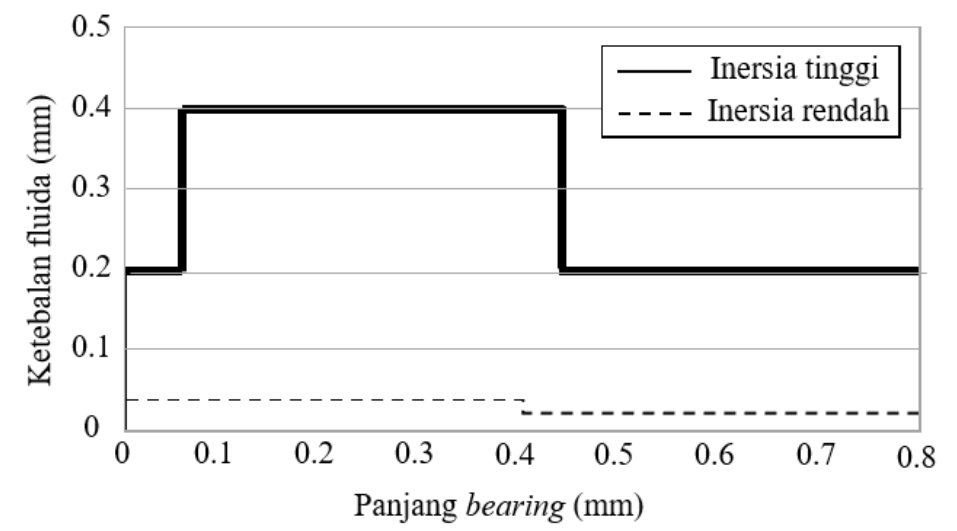

Gambar 2. Perbandingan pola geometri bearing dengan dua kondisi inersia yang berbeda

Tabel 1. Pendefinisian fasa

\begin{tabular}{clr}
\hline No. & \multicolumn{1}{c}{ Parameter } & Nilai \\
\hline 1 & Densitas pelumas $\rho$ & $860 \mathrm{~kg} / \mathrm{m}^{3}$ \\
2 & Viskositas dinamis pelumas $\eta$ & $0.03 \mathrm{~Pa}-\mathrm{s}$ \\
3 & Densitas uap air $\rho_{\text {vap }}$ & $1.256 \times 10 \mathrm{~kg} / \mathrm{m}^{3}$ \\
4 & Viskositas uap air $\eta_{\text {vap }}$ & $0.02556 \mathrm{~Pa}-\mathrm{s}$ \\
\hline
\end{tabular}

Dalam penelitian kali ini, untuk analisis pengaruh kekasaran permukaan, di sepanjang daerah dinding atas slider bearing (Gambar 1), kondisi kekasaran permukaan dengan tingkat tertentu diaplikasikan. Ada 4 tingkat kekasaran permukaan yang dipilih, yaitu $R_{a}=0.1 \mu \mathrm{m}$ (sangat halus), $R_{a}=0.4 \mu \mathrm{m}$ (halus), $R_{a}=1.6 \mu \mathrm{m}$ (medium), dan $R_{a}=12.5$ $\mu \mathrm{m}$ (kasar). Sedangkan dinding bagian bawah slider bearing merupakan bagian yang bergerak dengan kecepatan sesuai bilangan Reynoldsnya. Bagian atas serta area tekstur pada slider bearing merupakan bagian permukaan yang diam.

Solusi numerik. Dalam simulasi ini, mesh yang digunakan adalah quadrilateral dengan jumlah nodal 15.000 dan 30.000 berturut-turut untuk pola bearing dengan inersia tinggi dan inersia rendah. Asumsi gradien kecepatan nol dalam arah normal terhadap permukaan sliding digunakan untuk merepresentasikan aliran fully developed. Model aliran turbulen $k$-e realizable dan kondisi isothermal digunakan dalam analisa ini. Skema second order upwind diaplikasikan untuk diskretisasi momentum, sedangkan prosedur SIMPLE digunakan untuk pressure-velocity coupling.

\section{Hasil dan pembahasan}

Akhir-akhir ini, kavitasi telah menjadi bahan kajian penelitian yang cukup intensif di berbagai kalangan peneliti, baik dari segi pemodelan matematisnya maupun fenomena fisiknya. Hal ini dikarenakan kavitasi dapat membawa pengaruh yang positif maupun negatif terhadap performa sistem mekanik (dalam kasus ini bearing). Asumsi pengabaian kavitasi dalam desain dan analisis pelumasan terbukti bisa mengakibatkan hasil kajian menjadi kurang akurat dan mendorong terjadinya pengambilan kesimpulan yang salah, terutama untuk bearing dengan perubahan geometri permukaan yang ekstrim seperti adanya tekstur yang dalam [11-12]. Oleh karena itulah, dalam penelitian ini, terkait dengan analisis pengaruh kekasaran permukaan terhadap performa slider bearing, dua pendekatan analisis pelumasan akan dilakukan, yaitu pertama, analisis dengan mempertimbangkan model kavitasi (Pers. 5 dan 6), dan kedua, analisis yang tidak memperhitungkan model kavitasi.

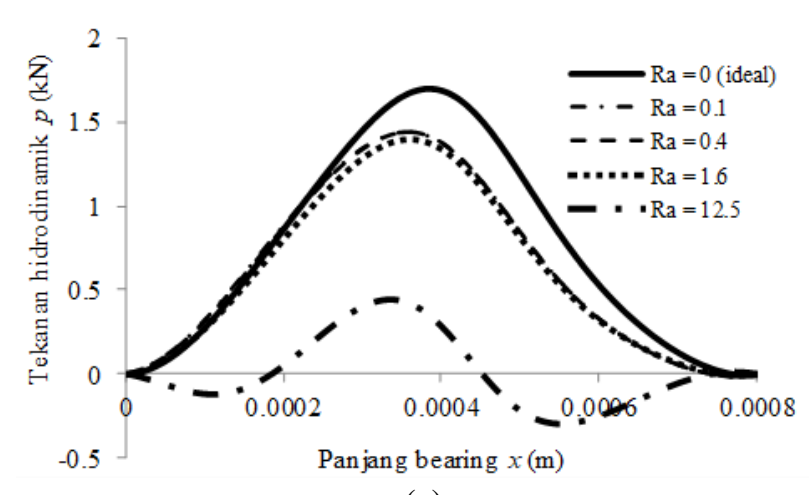

(a)

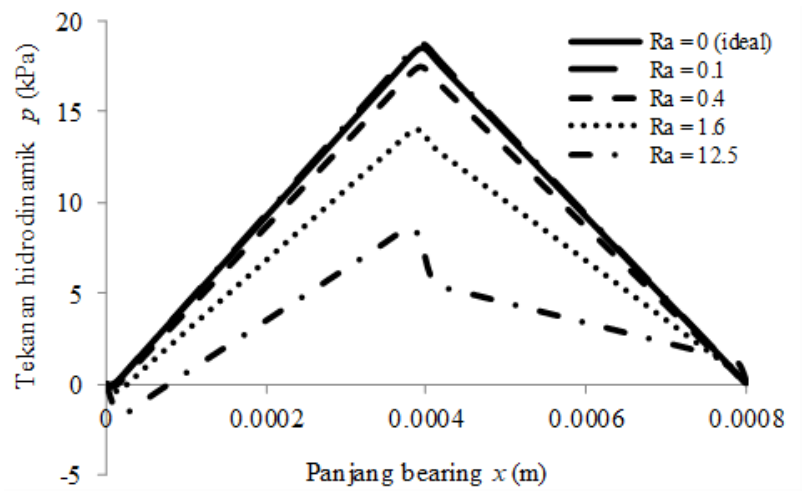

(b)

Gambar 3. Distribusi tekanan hidrodinamik tanpa memperhitungkan model kavitasi untuk kasus: (a) inersia tinggi, (b) inersia rendah 
Dalam penelitian ini, ada dua karakteristik performa hidrodinamik slider bearing yang dibahas, yaitu tekanan hidrodinamik $p$ dan daya dukung beban $W$ (load support). Daya dukung beban diperoleh dari hasil integral distribusi tekanan hidrodinamik di sepanjang permukaan kontak. Gambar 3 menunjukkan distribusi tekanan hidrodinamik pada berbagai tingkat kekasaran permukaan $\left(R_{a}=0.1 \mu \mathrm{m}, R_{a}=0.4 \mu \mathrm{m}, R_{a}=1.6 \mu \mathrm{m}, R_{a}=12.5 \mu \mathrm{m}\right)$ untuk dua pola bearing yang berbeda (inersia tinggi vs inersia rendah) dengan tidak mempertimbangkan model kavitasi.

Dari Gambar 3 ini tampak bahwa tingkat kekasaran permukaan yang diaplikasikan akan sangat berpengaruh terhadap distribusi tekanan pada slider bearing baik itu yang berpola "inersia tinggi" maupun yang berpola "inersia rendah". Untuk kedua pola bearing, ditemukan bahwa semakin tinggi nilai $R_{a}$ yang diaplikasikan yang berarti semakin kasar permukaan slider bearing, maka akan semakin turun distribusi tekanan hidrodinamik yang dihasilkan. Sebagai contoh, untuk bearing yang kasar $\left(R_{a}=12.5 \mu \mathrm{m}\right)$ dengan pola inersia rendah (Gambar 3(b)), tekanan hidrodinamik maksimum turun sebesar $137 \%$ jika dibandingkan dengan bearing ideal $\left(R_{a}=0\right)$. Hal ini menandakan bahwa dalam proses pembuatan bearing bertekstur, jika finishing untuk permukaan kontak nya tidak dilakukan secara hati-hati, maka ternyata bisa menurunkan performa slider bearing.

Gambar 3 juga menunjukkan bahwa terkait dengan pengaruh inersia, ketika bearing didesain agar memiliki inersia yang kecil (dengan cara mengatur agar $R_{e}$ kecil dan $\lambda$ besar), maka distribusi tekanan hidrodinamik menjadi jauh lebih besar jika dibanding bearing dengan pola "inersia besar". Dengan kata lain, dalam kasus ini, inersia membawa pengaruh negatif terhadap performa bearing.

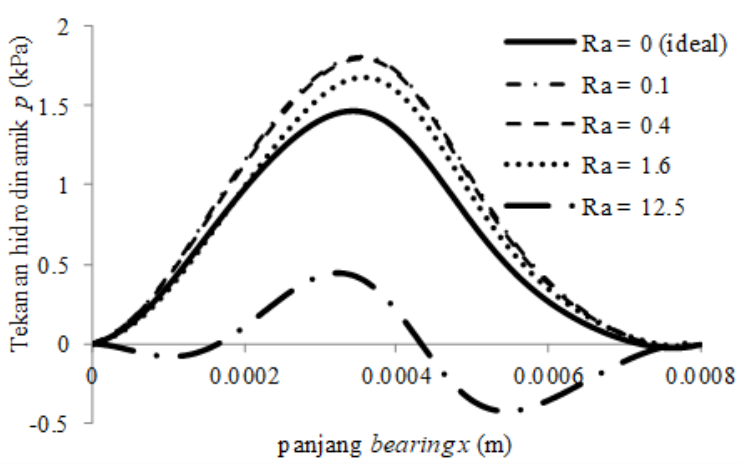

(a)

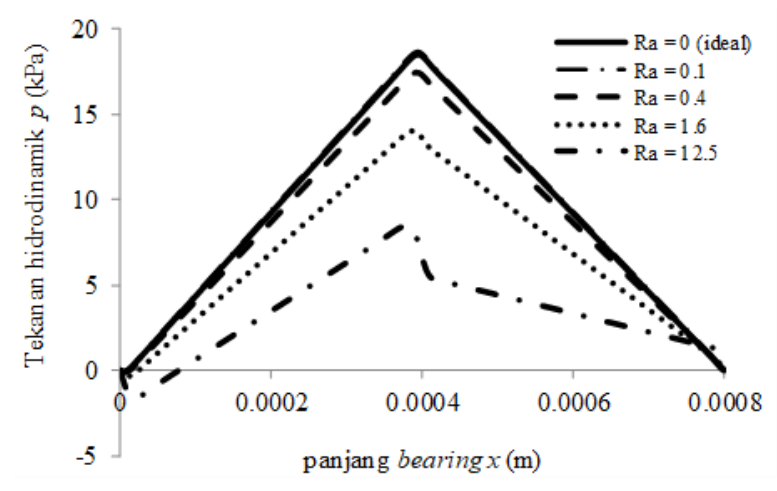

(b)

Gambar 4. Distribusi tekanan hidrodinamik dengan mempertimbangkan model kavitasi untuk kasus: (a) inersia tinggi, (b) inersia rendah

Untuk analisis pelumasan yang memperhitungkan model kavitasi, hasil simulasi distribusi tekanan hidrodinamik ditunjukkan dalam Gambar 4. Secara umum, jika dibandingkan dengan Gambar 3, ditemukan bahwa tekanan hidrodinamik yang dihasilkan dengan memperhitungkan model kavitasi menjadi lebih kecil untuk semua nilai kekasaran permukaan dan semua pola. Dari sudut pandang fisik, ini menandakan bahwa keberadaan kavitasi (gelembung-gelembung gas pada skala mikro) memberikan pengaruh negatif terhadap performa slider bearing. Pengaruh ini akan signifikan untuk bearing dengan inersia besar dan tidak terlalu signifikan untuk bearing dengan inersia kecil seperti diperlihatkan lebih detil pada Gambar 5.

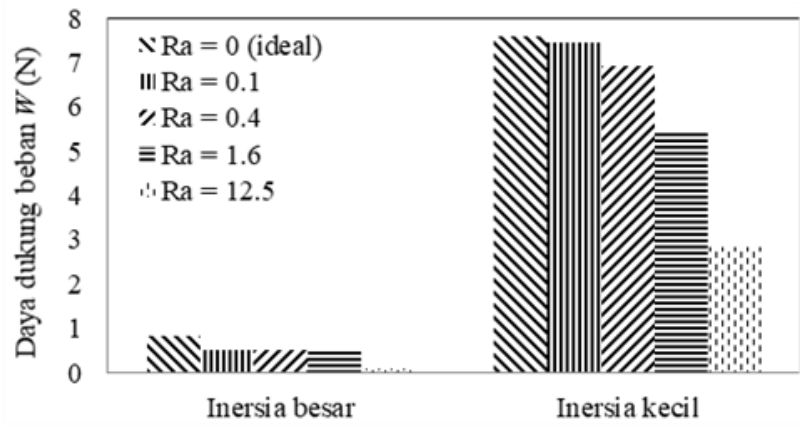

(a)

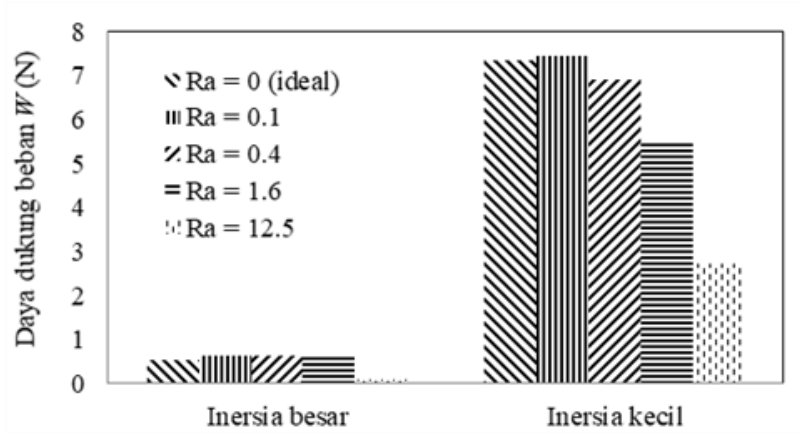

(b)

Gambar 5. Perbandingan daya dukung beban untuk kasus: (a) tanpa model kavitasi, (b) dengan model kavitasi

Gambar 5 menyajikan perbandingan daya dukung beban untuk dua pola bearing bertekstur (inersia besar vs inersia) untuk dua kondisi (kavitasi vs tanpa model kavitasi). Ada beberapa karakteristik daya dukung beban yang diperoleh dari Gambar 5 ini, yaitu, pertama, untuk kasus inersia kecil, perbedaan antara hasil analisis yang mempertimbangkan kavitasi dan yang tidak mempertimbangkan model kavitasi relatif sangat kecil (kurang dari 4\%). Dari sudut pandang 
fisik, ini menandakan bahwa kavitasi sebenarnya tidak terjadi pada bearing dengan inersia kecil. Kedua, untuk kasus bearing inersia besar, ada perbedaan prediksi daya dukung beban yang cukup signifikan, berkisar antara 15 - $37 \%$ tergantung dari nilai kekasaran antara analisis "kavitasi vs tanpa kavitasi". Dapat dikatakan bahwa terkait dengan Gambar 3 dan 4, untuk bearing dengan inersia besar, fenomena kavitasi dalam pelumas menyebabkan penurunan karakteristik hidrodinamika yang cukup signifikan.

\section{Kesimpulan}

Dalam penelitian ini, pengaruh kekasaran permukaan terhadap performa pelumasan slider bearing telah diinvestigasi. Dua jenis bearing yang berbeda kondisi inersia nya menjadi bahan kajian. Pengaruh pemodelan kavitasi dalam analisis juga telah diteliti. Dari hasil simulasi, dapat ditarik beberapa kesimpulan sebagai berikut: (a) Kekasaran permukaan memiliki pengaruh yang sangat signifikan terhadap tekanan hidrodinamik dan daya dukung beban. Makin besar tingkat kekasaran permukaan, makin berkurang daya dukung beban yang ditimbulkan. (b) Bearing bertekstur dengan pola desain inersia kecil menghasilkan performansi pelumasan yang jauh lebih baik dibanding pola desain inersia besar, karena ketiadaan kavitasi. Hasil penelitian ini diharapkan dapat menjadi panduan ketika melakukan proses manufaktur slider bearing terkait dengan hasil finishing permukaan kontak bearing.

\section{Daftar Pustaka}

[1] Cupillard, S., Glavatskih, S. and Cervantes, M.J., 2008. "Computational fluid dynamics analysis of a journal bearing with surface texturing," Proceedings of the Institution of Mechanical Engineers, Part J: Journal of Engineering Tribology, 222: 97-107.

[2] Cupillard, S., Glavatskih, S. and Cervantes, M.J., 2010. "Inertia effects in textured hydrodynamic contacts. Proceedings of the Institution of Mechanical Engineers," Part J: Journal of Engineering Tribology, 224(8): 751756.

[3] Rao, T.V.V.L.N., Rani, A.M.A., Nagarajan, T., and Hashim, F.M., 2012. "Analysis of slider and journal bearing using partially textured slip surface," Tribology International, 56: 121-128.

[4] Tauviqirrahman, M., Muchammad, Jamari and Schipper, D.J., 2014. "Numerical study of the load carrying capacity of lubricated parallel sliding textured surfaces including wall slip," Tribology Transactions, 57(1): 134145.

[5] Shi, X. and Ni, T., 2011. "Effects of groove textures on fully lubricated sliding with cavitation," Tribology International, 44(12): 2022-2028.

[6] Gururajan, K. and Prakash, J., 2001. "Roughness effects in narrow porous journal bearing with arbitrary porous wall thickness," International Journal of Mechanical Sciences, 44: 1003-1016.

[7] Naduvinamani, N.B., Hiremath, P.S. and Gurubasavaraj, G., 2002. "Effects of surface roughness on the static characteristics of rotor bearings with couple stress fluids," Computer \& Structures, 80: 1243-1253.

[8] Kalavathi, G.K., Dinesh P.A. and. Gururajan, K., 2016. "Influence of roughness on porous finite journal bearing with heterogeneous slip/no-slip surface," Tribology International, 102: 174-181.

[9] Adams T. and Grant, C., 2012. "A Simple algorithm to relate measured surface roughness to equivalent sand-grain roughness," International Journal of Mechanical Engineering and Mechatronics, 1: 66-71.

[10] Zwart, P. Gerber, A. and Belamri, T., 2004. "A two-phase flow model for predicting cavitation dynamics," Fifth International Conference on Multiphase Flow, Yokohama, Japan, May 30 - June 3, 2004, no. 152.

[11] Dobrica, M.B., Fillon, M., Pascovici, M.D. and Cicone, T., 2010. "Optimizing surface texture for hydrodynamic lubricated contacts using a mass-conserving numerical approach," Proceedings of the Institution of Mechanical Engineers, Part J: Journal of Engineering Tribology, 224(8): 737-750.

[12] Tauviqirrahman, M., Yohana, E. dan Hakim, A.R., 2016. "Analisa numerik pemberian slip dan tekstur untuk peningkatan performansi pelumasan pada bearing, “ Prosiding Seminar Nasional Tahunan Teknik Mesin (SNTTM) XV PM-018, 897-903, Bandung 5-6 Oktober 2016, Institut Teknologi Bandung. 